\title{
Career Gatekeeping in Cultural Fields
}

Julian Hamann, Leibniz Center for Science and Society, University of Hannover Stefan Beljean, Department of Sociology, Harvard University

\begin{abstract}
This paper presents a comparative analysis of career gatekeeping processes in two cultural fields. Drawing on data on appointment procedures in German academia and booking processes in North American stand-up comedy, we compare how gatekeepers in two widely different contexts evaluate and select candidates for established positions in their respective field and validate their decisions. Focusing on three types of gatekeeping practices that have been documented in prior research — typecasting, comparison, and legitimization — our analysis reveals major differences in how gatekeepers perform these practices across our two cases: (1) typecasting based on ascriptive categories vs. professional criteria, (2) comparisons that are ad-hoc and holistic vs. systematic and guided by performance criteria, and (3) legitimation by means of ritualization vs. transparency. We argue that these differences are related to the social and organizational context in which gatekeepers make selection decisions, including differences in the structure of academic and creative careers and the organization of the respective labor markets in which these careers unfold. These findings contribute to scholarship on gatekeeping in cultural fields by providing comparative insights into the work of career gatekeepers and the social organization of career gatekeeping processes.
\end{abstract}


These are proofs of the final publication available at Springer via American Journal of Cultural Sociology: https://doi.org/10.1057/s41290-019-00078-7

Cultural fields are competitive arenas for producers of cultural goods. What is at stake is not only the creation of valuable products, but also access to positions which bestow cultural producers with material security and symbolic recognition (Bourdieu, 1993). A key role in regulating access to such established positions is played by gatekeepers. Gatekeepers are actors who control access to desirable goods and positions in a field, and who thereby have an important impact on careers in cultural fields.

Because of the powerful positions they occupy, gatekeepers have received a good amount of attention in scholarship on cultural fields. The bulk of this research has concentrated on the social influences that shape gatekeepers' decisions (see Godart and Mears, 2009; Foster et al., 2011), as well as the consequences of their decisions for the fate of cultural producers and their products (see Bielby and Bielby, 1994; Zuckerman et al., 2003). Some scholars have also examined the evaluative practices and decision-making processes through which gatekeeping decisions are produced (see Posselt, 2016; Nylander, 2014).

Irrespective of the analytic focus of prior scholarship, however, gatekeeping has mostly been studied within the context of a given cultural field, for example, literature or music (see Franssen and Kuipers, 2013; Vermurlen, 2016). In this paper, we compare gatekeeping processes across fields to enhance our scholarly understanding of variation in both the social organization of gatekeeping processes and the gatekeeping practices that are mobilized by career gatekeepers in different fields. To this end, we conduct a comparative analysis of gatekeeping processes in two fields of cultural production: academia and stand-up comedy.

By adopting a comparative perspective, we build on a series of recent efforts to leverage the heuristic power of cross-field comparisons for theory building (for example, see Chong et al., 2019; Darr and Mears, 2017; Leschziner and Green, 2013). In addition, we respond to a recent call for more comparative research on valuation and evaluation as a social process (Lamont, 2012) by conceptualizing gatekeeping as a case for the sociology of valuation and evaluation (SVE). Building on the SVE literature, we adopt a process-centric perspective and 
These are proofs of the final publication available at Springer via American Journal of Cultural Sociology: https://doi.org/10.1057/s41290-019-00078-7

focus on three gatekeeping practices - typecasting, comparison, legitimation-by which gatekeepers in these two fields evaluate and select candidates for established positions and validate their decisions (see Lamont, 2012; Zuckerman, 2012). Our comparison reveals the different ways in which gatekeepers perform these seemingly uniform practices. Typecasting in stand-up comedy revolves around ascriptive categories and around professional criteria in academia. Comparisons tend to be systematic and guided by performance criteria in academia but largely ad-hoc and holistic in stand-up comedy. Lastly, gatekeeping processes are legitimized through transparency in academia but ritualization in stand-up comedy.

We purposively compare career gatekeeping processes in two vastly different cultural fields - a field of intellectual production and a field of popular entertainment - to maximize the contrast between our two cases. This facilitates a better understanding of the relationship of the social organization of gatekeeping processes and the gatekeeping practices that career gatekeepers rely on. A better understanding of this relationship is crucial, we argue, not only for scholarship on gatekeeping, but also students of inequality because of the powerful role that career gatekeepers play in shaping social mobility in cultural fields.

\section{GATEKEEPING IN CULTURAL FIELDS}

Artistic directors of theaters or operas, literary agents, booking agents for comedy festivals, and members of academic hiring committees have one thing in common: They belong to a select group of individuals who control access to both established positions and symbolic authority in their fields. ${ }^{1}$ Such positions are coveted because they bestow actors with

1 In using the distinction between established and unestablished positions, we build on prior sociological research on cultural fields that has described the transition from unestablished, outsider positions to established, insider positions as a crucial step in the careers of cultural producers (see Dowd and Pinheiro, 2013; Dubois and François, 2013). We acknowledge, however, that there is no universal, clear-cut definition of an "established" position. What constitutes an "established" position varies from field to field, and can be marked more or less formally (e.g., in some fields, there are formal titles for "established positions," such as "full professor" in academia, while in other fields these positions are identified in a less official manner). In the current analysis, we address the slipperiness of this term by using social actors' own intersubjective definitions of established and unestablished positions. 
These are proofs of the final publication available at Springer via American Journal of Cultural Sociology: https://doi.org/10.1057/s41290-019-00078-7

recognition and guarantee a basic level of material security. Further, symbolic authority allows actors to influence the future valuation of cultural goods (Bourdieu, 1993; Cattani et al., 2014). Thus, by controlling the mobility of cultural producers through either promotion and recognition or exclusion and rejection, literary agents, artistic directors, and comparable actors engage in "gatekeeping practices" (see Foster et al., 2011).

Gatekeeping practices belong to a broader category of mediating practices that regulate the legitimacy and distribution of resources as well as access to positions in cultural fields. ${ }^{2}$ These mediating practices include evaluation, networking, disseminating, marketing, and selling practices, and are performed by cultural mediators or intermediaries (Bessy and Chauvin, 2013; Janssen and Verboord, 2015; Khaire, 2017; Verdaasdonk, 2001). The function of cultural mediators can include several of these practices (see the example of art galleries, cf. Bystryn, 1978; Velthuis, 2003).

Prior studies have shown that gatekeeping practices in cultural fields can be performed by various types of actors, including newspaper or literary editors in publishing (Clayman and Reisner, 1998; Franssen and Kuipers, 2013); peers in academia (Hirschauer, 2010; Lamont, 2009); agents in the movie and music industry (Roussel and Bielby, 2015; Vermurlen, 2016); and critics in the art, culinary, and literary worlds (Chong, 2013; Greenfeld, 1988; Lane, 2013). Many of these gatekeepers have an influence on the careers of cultural producers by making decisions about cultural products, such as, for example, the role of peers in the anonymized evaluation of manuscripts for academic journals. But gatekeepers may also affect the career trajectories of cultural producers more directly by controlling access to established social positions. Although both types of gatekeepers may contribute to the production of inequality in cultural fields (Childress and Nault, 2018), for the purpose of this paper we are

2 Mediators are not restricted to cultural fields; in fact, the concept was first developed to demonstrate the decision-making power of housewives in household food decisions (Lewin, 1943). The first systematic applications occurred in research on mass media (cf. Shoemaker and Vos, 2009). 
These are proofs of the final publication available at Springer via American Journal of Cultural Sociology: https://doi.org/10.1057/s41290-019-00078-7

primarily concerned with the second type of gatekeepers. Because the decisions of these gatekeepers have a direct impact on career trajectories in cultural fields, we refer to them as "career gatekeepers."

A number of scholars have examined "career gatekeeping" in cultural fields. This literature has contributed to our knowledge on the factors that affect the decisions of career gatekeepers. For example, social networks influence the search and selection strategies used by booking agents for night clubs, academic peers involved in appointment procedures, and producers of fashion shows (Corra and Willer, 2002; Foster et al., 2011; Godart and Mears, 2009; van den Brink and Benschop, 2014). In addition, career gatekeepers' positions in a field influence their decisions, as researchers have demonstrated for agencies in the film industry and comedy scouts at art festivals (Bielby and Bielby, 1999; Friedman, 2014).

The literature on career gatekeepers has also produced important insights on the effects of gatekeeping decisions. For example, studies have highlighted the effect of these decisions on tastes in the respective fields. Comedy scouts intensify taste boundaries when they select comedians for gigs, and jazz teachers reify the artistic rules of the field of jazz music (Friedman, 2014; Nylander, 2014). In addition, a few studies on career gatekeeping have concentrated on the effects of gatekeeping decisions on employment chances; this work includes analyses of employment throughout the project-based careers of writers and actors in the film and television industry (Bielby and Bielby, 1999; Zuckerman et al., 2003). ${ }^{3}$

Lastly, scholarship on career gatekeepers has homed in on evaluative practices throughout the decision making process. These studies shed light on how career gatekeepers apply specific norms and ideas in their decision-making (Posselt, 2016; van den Brink and Benschop, 2012), how their evaluative work oscillates between notions of artistic uniqueness

It is worth noting that the foci of research on gatekeepers for cultural producers largely mirror the foci of research on gatekeepers for cultural products. Most strikingly, both literatures mostly draw on single casestudies, with few exceptions comparing cases within the same field (Greenfeld, 1988; Lane, 2013; Velthuis, 2003; Verboord, 2011). 
These are proofs of the final publication available at Springer via American Journal of Cultural Sociology: https://doi.org/10.1057/s41290-019-00078-7

and practical requirements of assessment procedures (Nylander, 2014), and how career gatekeepers in different fields search for and source local knowledge (Darr and Mears, 2017). In this paper, we aim to further contribute to this third line of research by shedding light on cross-field differences in how career gatekeepers make selection decisions and validate these decisions, and how these differences stand in relationship to differences in how career gatekeeping processes are organized in different types of cultural fields. In doing so, our paper takes up the assertion from cultural sociology that "[w]e need to know more about the thinking of gatekeepers" (Alexander and Smith, 2003: 18).

\section{TWO CASES OF GATEKEEPING IN CULTURAL FIELDS}

To increase the comparative leverage of our study, we chose two widely different cases for our comparison, employing what Bechky and O’Mahony (2015) call a “comparative matched pair design between dissimilar cases." Even though academia and stand-up comedy both represent cultural fields, they are characterized by vastly different labor market and career structures. Similar to the labor market of other cultural production industries, the labor market for stand-up comedians is an external labor market (Zuckerman et al., 2003; Reilly, 2017). Most stand-up comedians are therefore freelancers who work for many different employers. Moreover, career structures are marked by a low degree of standardization: there are no formalized ranks that denote the career stage of a comedian. Positions in the comedy industry are also fluid, depending on the demands of the market; even the most established positions are short-term and project-based.

Academic careers, in contrast, follow a much more formalized structure (Musselin, 2010). There are clearly delineated ranks for different stages of a career in academia, as indicated by categories such as "doctoral candidate," "post-doc," and "full professor.” Throughout academia, there is a shared knowledge of the characteristics and relative worth of each status 
These are proofs of the final publication available at Springer via American Journal of Cultural Sociology: https://doi.org/10.1057/s41290-019-00078-7

category (cf. Angermuller, 2017). In this system, full professors occupy the most established position. Thus, compared to the short-term contracts in the project-based labor market of stand-up comedy, the appointment of a full professor represents a substantial investment for a university. Rather than being employed for a few months or years, full professors are tenured and often stay at a university for several decades.

Crucially, German academia and North American stand-up comedy do not only differ in their labor market and career structures. As we will show in the following, there are also differences in the social organization of gatekeeping. While career gatekeeping for German professor positions is organized as a formal procedure that is embedded in an organizational context and guided by bureaucratic rules, gatekeeping in the North American stand-up comedy is organized as a public audition that is staged as a show. The case studies in the current analysis are: (1) appointments of professors in academia in Germany, in which members of committees, external reviewers, and top university administrators decide between candidates, and (2) stand-up comedy bookings in North America, in which comedians get hired for shows and signed for development contracts with television networks, production companies, and agents.

\section{Gatekeeping in Academia}

To understand career gatekeeping in German academia, it is important to be aware of some distinct features of the German academic labor market (see Musselin, 2010). While the job market for professors is federal, professors' salary is paid by one of the 16 states [Länder] and state ministries are directly involved in appointments. ${ }^{4}$

4 Professors have traditionally been hired by the minister representing the local state [Land]. This approach was based on a main principle of German higher education policy dating back to the early 19th century: Although universities were free to choose their faculty and could submit a shortlist to the rector (the head of the university), appointments were overseen by the states [Länder] in order to prevent nepotism. For the same reason, the local states were also in charge of budgets and positions. Reforms enacted in 2001 sought to provide 
These are proofs of the final publication available at Springer via American Journal of Cultural Sociology: https://doi.org/10.1057/s41290-019-00078-7

The main steps of professorial appointment procedures remained unchanged until today, and they follow a meticulous choreography: After the university administration approves a vacant position, an appointment committee is formed at the department level. Committees draft a public job advertisement and examine the applications, which include at least a cover letter, a curriculum vitae (CV), and a publication list. Based on the applications, committees identify a longlist of around ten candidates from usually several dozen applications.

Candidates from the longlist are invited for job interviews and afterwards assessed by external reviews from peers that are solicited by the committee. ${ }^{5}$ Reviews play an important role in the procedure. While committees mainly consist of faculty who will, for the most part, select their future colleague, most committee members are from fields that are adjacent to the research field of the vacant professorship. Drawing on the reviews, the applications, and personal encounters during talks and interviews, committees compile a shortlist of two to four applicants. Together with a document called laudation, the shortlist is submitted to subsequent decision making bodies in the university administration. The purpose of the laudation is to recommend the shortlisted candidates to the rector and the state ministry who formally offer the professorship - usually to the candidate at the top of the shortlist.

How exactly do appointment procedures influence the social mobility of professors in the field? A lack of success in one appointment procedure does not amount to exclusion from the field, as professorial candidates participate in several appointment procedures throughout their careers. Nonetheless, academic careers are fundamentally contingent upon professorial appointment procedures. While scholars in academic labor markets in other countries can obtain tenured positions at earlier stages (before being granted a full professorship), it is a

universities more autonomy in their hiring policies, and since then most states have transferred their right to appoint professors to the universities (see the overviews in Musselin, 2010; Möhlmann, 2014).

The number of reviews in an archival appointment record varies across the 145 appointment procedures in our sample. Most records include three to four reviews, while some outliers include nine or more reviews. A few archival records also do not include any reviews, which probably just means that the reviews have not been archived for this particular procedure. 
These are proofs of the final publication available at Springer via American Journal of Cultural Sociology: https://doi.org/10.1057/s41290-019-00078-7

particularity of the German university labor market that only full professors have tenured positions as civil servants, a status that brings material security (cf. Musselin, 2010). Usually, although not automatically, a full professorship also entails greater symbolic authority and visibility (see Angermuller, 2017), in part because individual professors have their own budget funds and research staff, for which they make autonomous hiring decisions.

In history, the discipline covered in the data, scholars usually transition to an established position - that is, their first full professorship — in their early 40s. In the 2000s, about 30 full professorships became available each year, which translates to a ratio of available professorships to candidates of 1:8. ${ }^{6}$ This ratio is somewhat cyclical; currently, a higher number of history professors are retiring or approaching retirement (Lincke and Paletschek, 2002). In certain ways, the labor market in the focal period of study (1955 to 1985) was less competitive. The educational expansion of the 1960s and 1970s brought many new positions, in part because several universities were founded during that time. This expansion explains why the median age for first appointment to a full professorship in history was 37.7 in 1977 (Lincke and Paletschek, 2002). ${ }^{7}$

\section{Gatekeeping in Stand-Up Comedy}

To study career gatekeeping processes in stand-up comedy, we focus on selection processes that are taking place prior and during the biggest annual convention of the North-American comedy industry: the Just for Laughs Festival (JFL Festival). Held every summer in Montreal,

6 This ratio does not consider differences between sub-disciplinary fields. In bigger fields like modern history the ratio is actually closer to $1: 13$.

7 It is a bit more complicated to hypothesize about the ratio between available professorships and candidates during the period of study. We know there were relatively more positions available. In several cases, the minutes of the meetings of appointment commissions actually note peers complaining about a lack of suitable candidates, or a lack of supply on the market. At the same time, the archival records facilitate a reliable overview of the applications for professorships, and these records suggest that, in the course of the educational expansion, the academic field was more open to newcomers and lateral entries, which would increase the number of candidates. 
These are proofs of the final publication available at Springer via American Journal of Cultural Sociology: https://doi.org/10.1057/s41290-019-00078-7

Canada, the JFL Festival occupies an important role in the North American field of stand-up comedy. It is not only attended by a large number of comedians but also a wide array of so called "industry representatives" who work for organizations that hire comedians, including television networks, agencies, and production companies. Apart from networking with other intermediaries in the field, these industry representatives visit the JFL every year to scout for new talent and sign comedians for contracts for a variety of jobs, including stand-up productions, TV shows and or acting roles. The festival thus serves as a central marketplace for the allocation of jobs and positions within the field of stand-up comedy. ${ }^{8}$

Our analysis of gatekeeping processes at the JFL Festival focuses on the Festivals' annual series of "New Faces" shows which have a field-wide reputation for being a crucial career springboard and rite of passage for stand-up comedians. Participation in one of these shows can lead to major career breakthroughs because the New Faces series is consciously designed by the festival organizers as a public audition where unestablished early-career stage comedians can vie for attention of key gatekeepers in the field of stand-up comedy.

This public selection process is roughly organized into two stages: an audition stage prior to the festival and the New Faces shows during the festival itself. During the audition stage, scouts working on behalf of the festival actively scout for comedians across the country and organize auditions in major cities across the United States (most importantly Los Angeles, New York City, and Chicago); they then invite 40-50 comedians to appear at the "New Faces" shows at JFL. The main gatekeepers at this stage of the process are comedy scouts that work for the festival. During the festival itself, the festival organizers typically hosts three to four New Faces shows, each featuring eight to ten comedians. Each of these comedians have a 5 to 10 -minute slot to perform a selection of their best material in front of an audience

In this regard, the role of the JFL Festival in the North American field of stand-up comedy is comparable to the Fringe Festival in the field of British comedy (studied by Friedman, 2014), as well as to similar fieldcoordinating events in other cultural fields, such as the fashion week in Paris (studied by Godart and Mears, 2009). 
These are proofs of the final publication available at Springer via American Journal of Cultural Sociology: https://doi.org/10.1057/s41290-019-00078-7

composed mostly of members of the comedy industry. The main gatekeepers at this stage are bookers working on behalf of television networks, agencies and other organization in the entertainment industry.

Compared to professorial appointment procedures, then, the JFL Festival presents us with a case of career gatekeeping in which gatekeeping is not cast as a formal bureaucratic procedure but as a tournament-like public selection process. The ultimate reward in this tournament is to land a development contract with a major entertainment organization, such as an agency, production company, or television network. In any given year, only a handful comedians succeed in obtaining such a contract at the JFL Festival. Most contestants return from the festival without receiving any immediate benefits. ${ }^{9}$ However, those comedians who are successful reap a wide array of benefits that are associated with obtaining a contract with a major "player" in the comedy industry, including an exposure to a much wider audience, improved financial security and contacts that can lead to future job opportunities. Via its New Faces shows, the JFL Festival thus contributes to central career gatekeeping processes in the field of stand-up comedy.

\section{DATA, METHODS, AND COMPARATIVE METHODOLOGY}

Our analysis of career gatekeeping processes in stand-up comedy and academia uses data from two different studies conducted by the authors. The analysis of professorial appointments draws on appointment records for 145 appointment procedures that took place between 1950 and 1985 at history departments at 16 German universities. ${ }^{10}$ The records

9 A scout working for the JFL Festival estimated that 250-300 comedians participate in the annual auditions for the festival (McCarthy, 2016). From this pool of comedians, about 40 receive an invitation to perform Montreal, which corresponds to about $13-16 \%$ of the initial pool of comedians participating in the auditions.

10 Access was requested from archives at 30 universities; 14 university archives were either not in possession of appointment records or denied access because they deemed that the retention period of the respective records was not over. Archival rights prevent access to records from appointment procedures after 1985 because participants are usually still alive. The sampled records vary with respect to several dimensions, such as age of the university, size of the department, and career stage of the candidates. 
These are proofs of the final publication available at Springer via American Journal of Cultural Sociology: https://doi.org/10.1057/s41290-019-00078-7

comprise documents that reveal the official narrative for the most important steps of professorial appointment procedures. Most gatekeeping practices, in particular those that are decisive for career trajectories, occur behind closed doors and are not accessible to researchers. However, because professorial appointments occur in an organizational context, important aspects of the gatekeeping process are documented in archived records. To be sure, this material provides data on the official aspects of the appointment, information that was considered appropriate for archiving. Recorded documents constitute an official front stage (see Prior, 2012). In terms of analytical potential, however, this does not make them less valuable than, for example, transcripts from participant observation. Rather, our data provide insight into what is considered to be the legitimate narrative of the appointment procedure. ${ }^{11}$ An important advantage of our archival data is that they cover the entire institutional procedure, from the job advertisement to the concluding negotiations between an applicant and the rector. Appointment records reveal the distinct stages of the process and allow us to analyze each stage, and thus are particularly suited to a study of the processual character of gatekeeping.

The analysis of gatekeeping processes in the field of stand-up comedy is based on data from an in-depth study of hiring processes in the North American stand-up comedy industry that was conducted between 2012 and 2014 (with a follow-up in 2016). As in academic appointment procedures, a large part of gatekeepers' evaluations of candidates occurs behind closed doors, and thus is not accessible for researchers. However, we were able to solicit accounts of gatekeepers involved in the selection process using qualitative interviews with long-term scouts working for the JFL Festival and a survey of bookers attending the festival.

11 Of course, archival records have their own peculiarities and limitations that must be considered. If this is achieved, alleged deficits become sociological phenomena in their own right, referring to the organizational and bureaucratic contexts in and for which appointment records are produced and received. Following Garfinkel (1967), there are 'good' organizational reasons for 'bad' records, and these reasons are highly relevant for sociological research. 
These are proofs of the final publication available at Springer via American Journal of Cultural Sociology: https://doi.org/10.1057/s41290-019-00078-7

In both the interviews and the survey we asked respondents to explain how they evaluate and select comedians. We supplement these data with ethnographic observations made at shows and social gathering points during the festival, as well as written accounts of the inner dynamics of the JFL Festival published by comedians and journalists.

The two case studies use different methods to study and compare gatekeeping processes, in part owing to the difference in the social organization of the two cultural fields we study. Professorial appointments are formal procedures that take place in formal organizations and thus leave documentary traces in archives. Booking processes at the JFL Festival, in contrast, are largely informal and are rarely systematically documented. Therefore, our study draws on different methods to gain insights into the structure of gatekeeping processes across our two cases. In doing so, we build on Mears (2014) who discusses how decision-making in cultural fields can be productively studied using an array of different methods.

However, there are also analytical challenges that come with pairing two case studies that use different methodological approaches. One important challenge is that the different methods of our case studies may depict gatekeeping processes in distinct ways. For example, the analysis of archival documents might convey the impression of gatekeeping as a rather bureaucratic procedure, while interviews could privilege narratives of field members about gatekeeping processes (cf. Lamont and Swidler, 2014). The design of our comparative study does not allow us to eliminate this possibility entirely. However, the primary aim of our study is to document variation in gatekeeping practices. Hence, the value of our comparative study does not necessarily rely on controlling the data sources between the two cases. We will return to this methodological question concerning our different methods and data sources when discussing the findings of our cross-field comparison. 
These are proofs of the final publication available at Springer via American Journal of Cultural Sociology: https://doi.org/10.1057/s41290-019-00078-7

\section{TYPECASTING, COMPARISON, AND LEGITIMATION IN GATEKEEPING}

\section{PROCESSES}

We use insights from existing research on gatekeeping and the sociology of (e)valuation (Lamont, 2012) to guide our comparative analysis of gatekeeping practices in gatekeeping processes in academia and stand-up comedy. This body of literature offers useful analytic distinctions for the study of the practices of career gatekeeping as it has drawn attention to a number of distinct practices that are a common part of gatekeeping in cultural fields. In this paper, we focus on three such practices — typecasting, comparison, and legitimation — with the goal to produce findings across several steps of the gatekeeping process (evaluation and validation) and to shed light on cross-field differences in how these practices manifest across different cultural fields.

By focusing on typecasting, we examine practices by which candidates ${ }^{6}$ employment opportunities in a labor market can be constrained due to their social attributes or prior employment history (cf. Faulkner, 1983; Zuckerman et al., 2003; Friedman and O'Brien, 2017). Employers frequently look for particular types in candidates based on the job they are hiring for and therefore evaluate candidates based on how well they fit that type. Second, we focus on practices of comparison by which career gatekeepers assess the relative strengths and weaknesses of different candidates. Such practices of comparisons can be more or less formalized (cf. Posselt, 2016), and the criteria mobilized for comparisons depend on the specific field context as well as gatekeepers' position within a given field (cf. Guetzkow et al., 2004; Nylander, 2014). Third, we focus legitimation as a practice by which powerful gatekeeping decisions are made comprehensible, plausible, and acceptable (cf. Bielby and Bielby, 1994; Franssen and Kuipers, 2013). Gatekeepers have to legitimize their decisions because they regulate access to established positions and thus contribute to the maintenance of inequality, and because gatekeepers are accountable to stakeholders for the decisions they 
These are proofs of the final publication available at Springer via American Journal of Cultural Sociology: https://doi.org/10.1057/s41290-019-00078-7

make. Analyzing practices of typecasting, comparison, and legitimation, we investigate the different forms these practices take in career gatekeeping in academia and stand-up comedy.

\section{Typecasting in Professorial Appointment Procedures}

Gatekeeping practices in professorial appointment procedures rely on typecasting, in which candidates are screened according to and matched with specific categories that are considered relevant for the job at hand. One important point of reference for the mobilization of said categories in professorial appointment procedures are published job advertisements. Most advertisements are comprised of only a few sentences that evoke a rather general and succinct profile of the ideal candidate. ${ }^{12}$ A typical example in our sample reads: "The following professorship is to be filled at [a university]: Professor for Ancient History. Remit: Among other fields, the applicant should have worked in constitutional and social history. Qualifications: Habilitation is required."13 Albeit they are rather brief and sober, job advertisements represent an important backdrop for the typecasting of candidates. The advertisements mobilize categories that are recognized in the field and thus inform the reviewers' and committee's assessments throughout the appointment procedure. As indicated by the above quote, the categories designate the research field that the future holder of the professorship is supposed to work in. By emphasizing expertise in specific research fields as an important criterion for candidates, job advertisements illustrate that academic labor markets are highly fragmented on the basis of intellectual specializations. Most professorships are designated to research fields when they are advertised; some of the fields are so small that the pool of candidates is limited to a few dozen that can meet this criterion.

12 Research on more recent job advertisements for German professors shows that the advertisements are becoming longer, include more criteria, and are thus more detailed (Klawitter, 2015). We do not observe such a development in our period of study.

13 All quotes have been translated from German. In order to guarantee anonymity for those involved in the procedures, we omit information that would allow the identification of individuals. 
These are proofs of the final publication available at Springer via American Journal of Cultural Sociology: https://doi.org/10.1057/s41290-019-00078-7

Importantly, the categories that are explicitly stated in the job advertisement are not the only categories that orient the committee's typecasting. They are complemented by more tacit categories that can nonetheless be equally important for the selection of candidates, but that are not always clearly defined and openly stated in an appointment procedure. For example, a department can have to cope with a large number of students and thus stress the importance of teaching skills, or pursue an implicit research agenda and make specific a research expertise of candidates a criterion. The subsequent expectations towards candidates are usually not made explicit in the job advertisement, but they can still be familiar to members of the department and the field alike. Both explicit categories from the job advertisement and tacit categories serve as anchors for subsequent typecasting.

Typecasting plays a paramount role in two situations throughout appointment procedures: We observe the first situation of typecasting in the external reviews that committees solicit from peers in the research field of the vacant professorship in question. Reviewers assess candidates according to research and teaching performance as well as their experience in administrative duties. The reviewers then match the candidates with the requirements set down in the job advertisements. For example, one reviewer in our sample introduced his review stating that he "examined the professional qualifications of [a candidate] according to the text of the job application". Another reviewer asserted that a candidate "meets the requirements stated in the job advertisement by all accounts." Only few reviewers go beyond the categories that are specified in the job advertisements and anticipate further expectations and demands for the vacant position. In an attempt to mobilize tacit categories, one reviewer explained:

The work of [a candidate] combines empirical rigor with theoretical penetration of problems. Because of his way of doing research, he appears to be especially suitable for the chair of 'Theory of History', whose occupant should not only have a theoretical interest, but be qualified by theoretically informed empirical historiography. 
These are proofs of the final publication available at Springer via American Journal of Cultural Sociology: https://doi.org/10.1057/s41290-019-00078-7

The second situation of typecasting takes place in the laudation, the document in which the committee rationalizes its selection of shortlisted candidates towards the subsequent decision making bodies within the university. While external reviewers can only ever try to anticipate the local demands for a vacant position, as they are, by definition, external to the appointing department, the committee is much more familiar with the specific expectations at the department. Thus, one committee deemed that a candidate would "definitely be qualified to fulfil the duties at [the appointing department]." Another committee stated more explicitly in its laudation:

In its choice of candidates for the shortlist, the committee has been led by the necessity to appoint a personality that has not only scientific achievements, but also the ability to effectively support the existing professors in accomplishing the educational and organizational duties in our overcrowded field.

Committees screen candidates according to categories that refer to local requirements and expectations of the appointing department. These concerns are mostly unknown to other participants of the procedure, candidates and reviewers alike, because they remain implicit throughout large parts of the procedure. While tacit categories play an important role for committees' typecasting, it is interesting to note that only few committees in our sample match the candidates' profile with the categories that are made explicit in the job advertisement.

\section{Typecasting in Booking Processes in Stand-Up Comedy}

Typecasting is also widely prevalent in career gatekeeping processes in stand-up comedy. However, in contrast to typecasting in professorial appointment procedures, typecasting in the field of comedy tends to revolve around a different set of categories. While decision-makers in appointment procedures frequently evaluate candidates based on professional criteria, 
These are proofs of the final publication available at Springer via American Journal of Cultural Sociology: https://doi.org/10.1057/s41290-019-00078-7

gatekeepers in stand-up comedy routinely evaluate candidates through the prism of ascriptive categories such as gender, race, sexual orientation, or age.

We find that candidates' social identity can shape gatekeepers' selection decisions in several ways. Probably the clearest case of typecasting we observe are so called 'diversity bookings.' This term refers to situations in which gatekeepers explicitly consider the social identity of candidates, typically with the intention to bring more attention to particular type of social identity that has previously been underrepresented in comedy or particular sub-markets of the field. Our data indicates that diversity bookings are most common during the audition stage through which comedians are selected to perform in Montreal. The bookers who are conducting these auditions are generally highly attuned to comedians' membership in racial, ethnic, or sexual categories. For example, one booker who is working for the JFL Festival organization explained in an interview: "You have to make sure you have a diverse list [of comedians], you know, gender, ethnicity, sexual orientation-we want to make sure to be representative of the entire community [...], you know, you don't want all white males." While it is not clear to what extent the promotion of diversity is a formalized goal for the organizers of the JFL Festival, we found remarkable consistency in the accounts of several bookers who are involved in this pre-selection stage. ${ }^{14}$

During the JFL Festival selection decisions also frequently involve typecasting but are undergirded by a different logic than diversity bookings. At this stage of the selection process, we can distinguish between two evaluative practices through which gatekeepers make selection decisions that rely on typecasting. First, bookers frequently consider the social identity of comedians when making selection decisions because they assume that comedians'

14 It is worth emphasizing, however, that the range of meanings of diversity that bookers consider tends to be relatively narrow. It is mostly limited to either gender and ethno-racial diversity, while other dimensions of diversity remain unconsidered. For example, few bookers consider age as an important source of diversity. This lack of attention to candidates' age is reflected in the line-ups of the Festival's annual New Faces shows, which are typically dominated by candidates in their early 20 s to $40 \mathrm{~s}$. 
These are proofs of the final publication available at Springer via American Journal of Cultural Sociology: https://doi.org/10.1057/s41290-019-00078-7

identity shapes their point of view as performers and the jokes they write. For example, a white working-class woman in her mid-30s who talks about her experiences as a single mom is deemed a very different type of comedian than a college-education, Asian, male performer who makes jokes about being gay. This intimate connection between comedians' identity and their comic material was frequently alluded to in interviews we conducted with bookers. Consider, for example, the following description that a scout of the JFL Festival offered in an interview:

There's a new SNL writer named Julio Torres who got Just for Laughs two years ago and he's extremely alternative. He's a gay guy from El Salvador and he likes to throw diamonds in the air. I'm like, 'he works much better at an upright citizens' style small black-box theater.' He's not going to do anything at Madison Square Garden but he's very funny and we don't want to lose out on that.

Our data indicates that the connection between comedians' identity and material is most salient to gatekeepers when booking comedians for conventional stand-up jobs, such as TV specials or produced shows. In this situation, gatekeepers essentially play the role of matchmakers (Friedman, 2014): Their job is to select a particular type of comedian whose comic personae and material represent a good match for a given target audience. As one booker explained this form of gatekeeping decision: "For this [name of TV show] we would book a lot of female comedians because we had to appeal to a lot of American soccer moms, but many of those comedians would not have been strong enough for the [name of late night TV show] which we also produce.”

We can distinguish a second practice of typecasting during the JFL Festival that is not oriented towards the material of the comedians, but towards their fit for TV or movie roles. Since the festival also attracts intermediaries working on behalf of agencies, movie studies and television companies, comedians may not only get hired for traditional stand-up comedy jobs, but also for roles in scripted TV or movie productions. Such acting jobs typically come 
These are proofs of the final publication available at Springer via American Journal of Cultural Sociology: https://doi.org/10.1057/s41290-019-00078-7

in the form of clearly defined roles which means that gatekeepers who are seeking to hire comedians for such roles typically have a very clear agenda of what type of comedian they are looking for when attending the annual JFL Festival: They may be producing a show for television for which they are scouting for a young Asian comedian, or they may be representatives of a Hollywood talent agency seeking to add a Latina actor to its roster. Since stand-up comedy is a cultural field with strong ties to television, film and other branches of the entertainment industry where such typecasting has been shown to be widespread (see Zuckerman et al., 2003), it should not come as a surprise that it is also widely prevalent in stand-up comedy.

Summing up, typecasting in stand-up comedy revolves around ascriptive categories like gender or race that concern the candidates' social identity. While the categories of the typecasting are mostly explicit and accessible to all participants of the booking process, typecasting can serve different purposes: It can take the form of politically motivated 'diversity bookings', it can be oriented towards the comedians' material, or towards their fit for specific TV or movie roles.

In contrast, the typecasting of gatekeepers in professorial appointment procedures is mostly oriented towards professional criteria that are either explicit and stated in the job advertisements, or they remain tacit and thus not easily accessible to all participants of the procedure. The typecasting appears to serve the single purpose of finding the candidate that is the best fit for the vacant position (see table 1).

\section{Comparison in Professorial Appointment Procedures}

Comparison is another important gatekeeping practice in both bookings in stand-up comedy and professorial appointment procedures. In the case of professorial appointments, 
These are proofs of the final publication available at Springer via American Journal of Cultural Sociology: https://doi.org/10.1057/s41290-019-00078-7

committees draw on explicit and often rather extensive comparisons of candidates.

Comparisons play an important role at the screening stage at the beginning of the appointment procedure, when committees have to compare many very different candidates according to a set of common criteria. At this stage, committees systematically compare candidates according to criteria stated in the job advertisement. Some of these criteria are straightforward and easy to determine (for example, candidates' age, and when they have completed the habilitation) while other criteria are more ambiguous and harder to assess (for example, candidates' international orientation, and how well their research matches the research agenda stated in the job advertisement). With respect to the first type of qualifications (straightforward), one reviewer in the sample suggested to the committee that, "several applicants in the final selection are habilitated, while others have not yet got over this examination procedure.” A note from a committee meeting provides an example of a more ambiguous criterion, stating that, "according to the job advertisement, only those applicants should be longlisted that have so far been working in the fields of late antiquity or early Middle Ages. A declaration of intent for future work in these fields is not sufficient." This quote shows that committees draw on specific criteria to sort and diminish the field of candidates to a more manageable size.

As part of their deliberation process, committees also draw on comparisons that are conducted by the external reviewers. Many reviews explicitly compare the candidates. This is a demanding task, as emphasized by one reviewer on our sample:

I am glad that, with the six colleagues that the committee asked me to review, six renowned scholars have applied [for the professorship]. [...] As fortunate as this list of applications might be for the department, it somehow leaves the reviewer in a tight spot: He has to establish an order where he perceives less a gradation in quality, but, rather, different distributions of scholarly interests. 
These are proofs of the final publication available at Springer via American Journal of Cultural Sociology: https://doi.org/10.1057/s41290-019-00078-7

Reviews usually compare candidates by discussing them consecutively and then relating them to each other at the end of the review, a direct and explicit comparison that is often incorporated into the decision that the committee makes on the shortlist. One reviewer concluded that "the academic achievements of [a candidate] are not fully evolved, particularly not in comparison with [another candidate]." It is rare that reviewers' comparisons are as clear cut as in this statement. Usually, comparative assessments are more nuanced, weighing different professional criteria. In their comparison, external reviewers mobilize criteria that are concerned with research and teaching performance as well as administrative credentials. The research foci of the candidates and the scope of their publications are particularly important. One candidate in the sample was deemed inferior to other candidates because "the methods he applies and his research questions are neither as diverse nor do they as systematically include the neighboring discipline as demonstrated by [a preferred candidate]." Many reviews end with a rank order of candidates. One reviewer openly admits that these rank orders can be rather fragile: "I want to emphasize that I am only recommending this distinct rank order because [...] this has been requested from the committee. I will not conceal that I could argue for and justify any other order." These rank orders precede the shortlist of the committee, sometimes they are even presented as an explicit suggestion by the reviewers. In fact, as we will show in the following section on legitimation, many committees refer to the reviews to legitimize their shortlist.

The committee justifies its selection of shortlisted candidates in the laudation, a document that serves two purposes: to praise the entire slate of candidates on the shortlist while simultaneously conveying a finely nuanced gradation between the remaining applicants. This gradation is primarily based on the candidates' respective quality in terms of research, teaching, and administrative duties. Some laudations are not comparative, but individually assess shortlisted candidates on their own. However, most laudations contain plentiful and rich comparisons. For example, one laudation concluded: 
These are proofs of the final publication available at Springer via American Journal of Cultural Sociology: https://doi.org/10.1057/s41290-019-00078-7

Each of the three applicants is qualified to represent the subject of ancient history at the University of Frankfurt. However, [one applicant] should—not without once again highlighting his competences and achievements—-be nominated behind [two other applicants] in view of his academic work up to now.

Many laudations also relate their comparison to the typecasting described in the previous section. For example, one committee stated that "the requirement of thematic breadth and sound research that has been leading the selection of the committee has been fulfilled best by [a candidate] in comparison to the other candidate." Another laudation praises a candidate, but ultimately comes to the conclusion that, "with view on the job advertisement, [a candidate] is clearly behind the two candidates at the top of the shortlist."

\section{Comparison in Booking Processes in Stand-up Comedy}

Drawing comparisons between candidates is also a common practice of career gatekeepers in stand-up comedy, but there are important differences with respect to how gatekeepers engage in these comparisons. First, we find that gatekeepers' comparisons of candidates in the case of stand-up comedy are not as systematic as in professorial appointment procedures and remain largely ad-hoc. Second, we find that gatekeepers in stand-up comedy tend to compare candidates holistically rather than draw on specific criteria of comparison.

The holistic character of comparisons is well illustrated by the practices of gatekeepers at the audition stage for the JFL Festival. At this stage, scouts and bookers working for the JFL Festival hold live auditions in comedy clubs across the United States with the goal to select a small number of comedians for the Festival's "New Faces" series. As part of these auditions, aspiring comedians typically get a chance to perform a 5 to 10 minutes set in front of a live audience and bookers of the JFL Festival. This format naturally invites bookers to draw comparisons between different candidates. However, instead of comparing candidates based 
These are proofs of the final publication available at Springer via American Journal of Cultural Sociology: https://doi.org/10.1057/s41290-019-00078-7

on a range of clearly defined criteria, bookers typically focus on their overall impression of comedians' stage performance. For example, one JFL booker stated: “Of course, I'm looking for stage presence, and timing, but in the end, it is whether it engages you, whether it captivates you, intrigues you in a way that get you thinking." This statement illustrates that even though there are some specific criteria that bookers could use to draw comparisons between candidates (for example, "timing" or "stage-presence"), bookers typically assess comedians' performance (and potential) holistically. This is not to say that gatekeepers do not occasionally rely on a number of more specific criteria of comparison. For example, they may consider a comedian's age or past achievement and compare it to that of another candidate. However, such focused comparisons of candidates are not given the same weight as comparisons that are guided by holistic overall impressions, and they are rarely conducted in a systematic way. This leads us to the second difference that our analysis reveals: The ad-hoc nature of gatekeepers' comparisons.

Gatekeepers' reliance on ad-hoc comparisons is particularly well illustrated by the process through which booking decisions are made during the JFL Festival. Above we have described how professorial appointment processes involve external reviews and other formal steps through which candidates are systematically compared. In contrast, booking processes at the JFL festival do not involve formalized document-based comparisons between candidates. In our ethnographic research at the JFL Festival, we find no evidence that bookers systematically compare candidates to each other before making hiring decisions. While doing observations at several New Faces shows, we did not observe any bookers taking systematic notes on comedians' performances. Instead, bookers seem to conduct their comparisons largely spontaneously and ad-hoc. Hence, bookers base their hiring decisions primarily on their overall impression of comedians' performance during the Festival's New Faces shows as well as hear-say about comedians' reputation, which bookers solicit through gossip, rather than a formal document-based process. 
Summing up, we find that candidates in stand-up comedy are not compared according to specific criteria, but rather holistically, following the bookers' overall impression of their performance on stage. In addition, gatekeepers' comparisons of candidates do not rely on a formal procedure or formal devices, but remain largely ad-hoc.

In contrast, comparisons in professorial appointment procedures are not ad-hoc, but drawn in a rather systematic fashion. Comparisons are conducted explicitly and supported by the documents like reviews and laudations, and the formal conventions that come with them. Comparisons are also not primarily guided by gut-feeling, but mainly by specific performance criteria that are established in the field (see table 1).

\section{Legitimation in Professorial Appointment Procedures}

Consistent with prior scholarship on gatekeeping (see Bielby and Bielby, 1994; Franssen and Kuipers, 2013), we find that gatekeepers in academia and stand-up comedy not only make powerful selection decisions, but also need to legitimize these decisions to various stakeholders. In the case of professorial appointment procedures, the legitimation of selection decisions is particularly important because of the diverse set of stakeholders that are involved in appointing professors, including faculty members of a given department, the university's administrative authorities and the responsible state ministries. Appointment decisions must therefore not only be accepted locally, but also across different levels of a formal bureaucratic organization. What is more, the legitimacy of appointment procedures is also crucial because they entail moments of refusal and rejection, which can increase precariousness and exclude certain individuals.

One factor that increases the legitimacy of evaluations in appointment procedures is the use of external reviews in which peers in the field assess the candidates at the request of the 
These are proofs of the final publication available at Springer via American Journal of Cultural Sociology: https://doi.org/10.1057/s41290-019-00078-7

committee. Support from external peers stabilizes the evaluation of the committee, because the third-party endorsement lends the evaluation credibility. This was apparent in a laudation in which a committee explicitly quoted from an external review, stating that "according to the judgment of acknowledged senior scholars of early modern history, [a candidate] is 'in the top bracket of younger modern historians in Germany."' Another exemplary laudation in the sample stated that "all external reviewers agreed that [a candidate] belongs to those younger historians in Germany that have a determining influence on the social scientific realm of historical research."

The legitimizing function of reviews becomes most strongly apparent when reviewers do not support candidates that are favored by a search committee. These cases are rare in our sample, but they make clear that it is extremely difficult for a committee to shortlist a candidate that is not endorsed by the reviewers. Reviews ensure that judgments are supported by scholars outside the committee and thus appear uncontroversial. However, the legitimizing role of external reviews is a peculiar one: While the official function of the external reviews is to present an impartial judgment of the candidates, it is clear from our data that in some appointment procedures, committees merely expect reviewers to affirm their decisions about which candidates to shortlist. This backstage aspect of the procedure is not always visible in archived appointment records, but the data do reveal some exceptions. For example, one scholar who was solicited to write a so-called courtesy review (Gefälligkeitsgutachten) expressed his ethical concerns, stating that these "reviews not only serve a merely confirmatory function, but downright request a confirmation of the previously made decision."

The data revealed a second strategy that facilitates the legitimation of gatekeeping decisions in appointment procedures: participants of the procedure make the decision making process transparent - at least certain parts of it. While most steps of appointment procedures are closed to the public, departments and committees nonetheless make some efforts to 
These are proofs of the final publication available at Springer via American Journal of Cultural Sociology: https://doi.org/10.1057/s41290-019-00078-7

provide insights into how these decisions are made. ${ }^{15}$ One step that increases the transparency of the procedure is the public advertisement of vacant professorships. This is a relatively recent development; the data reveal that as recently as the early 1960s reviewers simply suggested candidates to the committee without a formal job advertisement or application on the part of the candidates. A number of other measures that ensure transparency were also introduced during the 1960s: Committees began to take minutes of their meetings and to document who served on the committee. Some universities in our sample even oblige committees to compose reports of the appointment procedure. Documenting every important step of the procedure and including all relevant documents, these reports often exert 50 pages. One of the most important measures to facilitate transparency is the archiving of documents central to the process. This transparency of certain parts of the appointment procedure not only allows for scholars to study appointment procedures in retrospect as we do here, but more importantly legitimizes the final decision, because it provides documentation of the reasoning for certain evaluative decisions, and thus makes the parties involved in the procedure accountable for their decisions.

\section{Legitimation in Booking Processes in Stand-Up Comedy}

The legitimacy of gatekeeping decisions also plays an important role in stand-up comedy. Although the established positions that gatekeepers control in stand-up comedy are less permanent compared to a lifetime position of a German professor, bookers still need to ensure to reach selection decisions that find acceptance by various outside audiences. In the case of

15 Because the production of transparency is a complex issue, it is worthwhile to briefly return to the peculiar character of archived appointment records as data, which we discuss in the previous section on data and methods. Drawing on archived records, we must assume that documents, even when their purpose is to provide transparency, do not have a revelatory character that exposes how decisions were really made (whatever this is supposed to mean precisely). It is more realistic to assume that the archived documents are part of a bureaucratic front stage on which legitimate decision-making procedures are performed (Prior, 2008). However, even if transparency is only performed, it has legitimizing and stabilizing effects (Flyverbom et al., 2015; see also Power, 1997). 
These are proofs of the final publication available at Springer via American Journal of Cultural Sociology: https://doi.org/10.1057/s41290-019-00078-7

the JFL festival, this includes the candidates that gatekeepers are evaluating (and those they are rejecting), the leaders of the organizations they are working for (TV network executives, agency bosses etc.) as well as members of the broader stand-up comedy community, including already established comedians.

How do bookers legitimize their selection decisions in eyes of these external audiences? Our analysis of the JFL Festival suggests that bookers seek to bolster the legitimacy of their gatekeeping decisions in two main ways. First, and remarkably similar to gatekeepers in professorial appointment procedures, bookers extensively rely on the judgment of other actors to inform their own selection decisions. They consult the opinions of other gatekeepers, comedy critics, comedy consumers and already established comedians to get a more accurate estimation of the "value" of individual comedians who are vying for attention at the JFL Festival. In some cases, gatekeepers rely on the judgment of these other actors as a point of orientation to get a sense of which comedians to watch out for during JFL. For example, one gatekeeper we interviewed explained how he determined which comedians he paid attention to at the festival: "I listened to a selection of comedy whispers, asking them what they think, who is currently hot in the scene, and who the industry thinks is going to pop soon." In other cases, gatekeepers may rely on third-party evaluations to validate and justify booking decisions post-hoc. For example, if a particular comedian performing at the JFL has received an exceptional degree of attention from comedy critics prior to the festival, gatekeepers can use this information as an argument to justify their selection decisions within the organization they are working for.

Second, we find that gatekeeping decisions in stand-up comedy also derive legitimacy from the way the JFL Festival structures the process through which early-stage comedians are selected for lucrative jobs. The New Faces series of the JFL Festival utilizes a cultural form that is well-established in the cultural industries and performing arts: that of a public casting or audition where candidates perform short samples of their craft in front of judges and a live 
These are proofs of the final publication available at Springer via American Journal of Cultural Sociology: https://doi.org/10.1057/s41290-019-00078-7

audience (cf. Muniesa and Helgesson, 2013). By mobilizing this widely familiar cultural script, the annual selection process of the JFL Festival takes on a highly ritualized form: it is not only scripted (and thus predictable), but also takes place in front of an audience which according to sociological theories of ritual is crucial for the legitimacy of the outcome of a ritual (Collins, 2004).

This ritual-like character is discernible already at the audition stage in the months running up to the festival. Auditions largely take the same form year after year, and are typically widely publicized in local stand-up comedy circles via websites and social media. Large numbers of early-career stage comedians are looking forward to these auditions with great anticipation. Later, during the festival itself, the ritual-like character of the selection of comedians is even more pronounced. With its New Faces shows, the festival has created a distinct format dedicated to the selection of up-and-coming comedians which has been running in largely unchanged form for more than 20 years. As such, the New Faces series has become a major focal point for insiders of the field of stand-up comedy. Every year, the festival is also extensively covered by press representatives who report on the happenings of the JFL. This press coverage is closely followed by comedians and bookers in the entire field. News about which comedians were discovered at the Festival in a given year quickly becomes common knowledge in the field. Thus, ultimately, the competition for entry into the top segment of the comedy industry during the annual JFL Festival occurs under the watch of the entire comedy community.

Summing up, gatekeeping decisions in stand-up comedy derive legitimacy from the way the JFL Festival structures the process according to the familiar and ritualized cultural script of a public casting or audition. Bookers also attempt to back up their decisions by third party endorsements, i.e., by seeking the judgment of other gatekeepers to inform their own selection decisions. 
These are proofs of the final publication available at Springer via American Journal of Cultural Sociology: https://doi.org/10.1057/s41290-019-00078-7

Third party endorsements are also an important source of legitimacy in professorial appointment procedures, where external reviews lend the committees' decisions credibility and make them appear uncontroversial. In further attempts to legitimize gatekeeping decisions, participants of the procedure also seek to make parts of the decision making process transparent (see table 1).

Table 1: Differences and similarities in gatekeeping processes in academia and stand-up comedy $^{16}$

\begin{tabular}{|l|l|l|} 
& $\begin{array}{l}\text { Appointment procedures for full } \\
\text { professors at German universities }\end{array}$ & $\begin{array}{l}\text { Selection of comedians for } \\
\text { contracts during annual JFL } \\
\text { Festival }\end{array}$ \\
\hline Typecasting & $\begin{array}{l}\text { Oriented towards professional criteria } \\
\text { Serving a single purpose: fit }\end{array}$ & $\begin{array}{l}\text { Revolving around ascriptive criteria } \\
\text { Serving multiple purposes: political, } \\
\text { material, fit }\end{array}$ \\
\hline Comparison & $\begin{array}{l}\text { Oriented towards specific performance } \\
\text { criteria } \\
\text { Conducted in a systematic fashion }\end{array}$ & $\begin{array}{l}\text { Holistic, based on overall impressions } \\
\text { Conducted ad-hoc, guided by gut- } \\
\text { feeling }\end{array}$ \\
\hline Legitimation & $\begin{array}{l}\text { via third party endorsements by peer } \\
\text { reviews } \\
\text { via transparency of certain parts of the } \\
\text { procedure }\end{array}$ & $\begin{array}{l}\text { via third party endorsements by other } \\
\text { gatekeepers } \\
\text { via the ritualized cultural script of a } \\
\text { public audition }\end{array}$ \\
\hline
\end{tabular}

\footnotetext{
16 The differences in the table are to be understood as gradual rather than absolute.
} 
These are proofs of the final publication available at Springer via American Journal of Cultural Sociology: https://doi.org/10.1057/s41290-019-00078-7

\section{DISCUSSION: UNDERSTANDING VARIATION IN CAREER GATEKEEPING}

\section{PRACTICES IN CULTURAL FIELDS}

In the preceding analysis, we have compared the practices of career gatekeepers in two widely different cultural fields. Despite the differences between our two cases, our analysis shows that career gatekeepers draw on similar practices. Gatekeepers in professorial appointment procedures and in stand-up comedy engage in practices of typecasting, comparison, and legitimation when controlling access to desirable positions in their fields. The prevalence of these practices even across widely different fields replicates and bolsters findings from the gatekeeping literature (see Zuckerman et al., 2003: on typecasting; Nylander, 2014: on comparison; Chong, 2013: on legitimation). However, we also identify major differences in how gatekeepers perform these practices across our two cases (see table 1) — which is a novel contribution to the literature on career gatekeeping.

As we will discuss further below, the interpretation of the results of our comparative analysis requires some caution due to the methodological design of our cross-field comparison. Nonetheless, we believe that at least some of the findings of our research can be tied back to two structural differences between our two cases: the different social organization of career gatekeeping in academia and stand-up comedy as well as the different labor markets and career structures that we find in each field. While career gatekeeping processes in the case of German academia is organized as a bureaucratic procedure, gatekeeping in stand-up comedy is organized as a public spectacle. Moreover, while academic labor markets are marked by standardized career structures, careers in stand-up comedy tend to be much more irregular because of the project-based nature of its labor market. In the following few paragraphs, we discuss how these particularities of our cases relate to the differences in typecasting, comparisons, and legitimations that we have revealed. 
These are proofs of the final publication available at Springer via American Journal of Cultural Sociology: https://doi.org/10.1057/s41290-019-00078-7

With respect to typecasting, we found that typecasting in professorial appointment procedures is mostly oriented towards professional criteria, and that it serves the purpose of establishing a fit between candidates and the vacant position. We propose that this emphasis on fit may be attributed to the social organization of professorial appointments: They represent procedures that are embedded in the university as the very organizational setting that the given vacant position is located in. More generally, professional criteria and the candidates' fit are crucial because the appointment of a full professor in Germany represents a substantial commitment for the university. Full professors are tenured, they sometimes stay at a university for several decades. Thus, the efforts that committees make to find a suitable candidate that matches the profile of a vacant position as close as possible may be the result of the considerable commitment that a professorial appointment entails. In contrast, typecasting in stand-up comedy revolves more strongly around ascriptive categories that concern candidates' identities, for example, as 'blue collar,' 'female,' or 'ethnic' comedians. While many ascriptive categories may not carry much legitimacy in the context of bureaucratic organizations that have embraced merit-based principles of recruitment, they play an outsized role in entertainment industries such as stand-up comedy because producers' identities are treated as pertinent to the very work they perform. Additionally, we found that typecasting in stand-up comedy may serve multiple purposes: Gatekeepers may consider the social identity of candidates to increase diversity, engage in cultural matching (between comedians and potential audiences), or select comedians for jobs that require a particular identity. We argue that this may be the case because the JFL Festival mediates access to a range of desirable positions in the field of stand-up comedy, and not just one type of position as in the case of professorial appointment procedures: Gatekeepers attending the JFL Festival may hire comedians for classical stand-up comedy shows, acting roles, writing jobs etc.

With respect to comparisons, we have shown that career gatekeepers in stand-up comedy compare candidates primarily ad-hoc and in a holistic fashion. We propose that this dominant 
These are proofs of the final publication available at Springer via American Journal of Cultural Sociology: https://doi.org/10.1057/s41290-019-00078-7

mode of comparison is related to the specific social organization of the JFL Festival and its New Faces shows. The New Faces series and their preceding auditions are framed as a public spectacle that puts candidates and their stage persona in the limelight. Meanwhile, the actors who evaluate comedians remain largely in the background and are exposed to only little scrutiny. Thus, gatekeepers in stand-up comedy can afford to draw comparisons between candidates that are ad-hoc and holistic because they are less accountable to outside audiences than members of academic appointment procedures. In addition, we believe that the ad-hoc and holistic character of gatekeepers' comparison is also influenced by the low degree of standardization of careers in stand-up comedy. Because there are no formalized ranks that separate different career stages in stand-up comedy, there is no shared understanding of what skills, credentials, and accomplishments individual producers need to have accomplished by a given career stage - thus offering gatekeepers fewer tangible reference points to draw comparisons between candidates.

In contrast, career gatekeepers in professorial appointment procedures engage more extensively in comparisons. We have shown that their comparisons are often guided by specific performance criteria and conducted in a rather systematic and formalized fashion. We suggest that the formalized character of comparisons can be explained by the bureaucratic, procedural character of appointment procedures, in which principles of procedural justice require that all candidates be evaluated identically. This is accomplished through formalized documents such as reviews or laudations which invite systematic comparisons of candidates at several points of the selection process. Moreover, we argue that the use of tangible performance criteria is related to the comparatively standardized stages of academic careers ( $\mathrm{PhD}$ candidate, post-doc, professor, etc.). The rather standardized structure of academic careers enables gatekeepers to orient their comparisons towards professional criteria that are tailored to specific career stages. 
These are proofs of the final publication available at Springer via American Journal of Cultural Sociology: https://doi.org/10.1057/s41290-019-00078-7

Lastly, with view on practices of legitimation, our analysis has shown that members of professorial appointment procedures rely on third party endorsements via external reviews, as well as efforts of rendering the decision making process transparent. We argue that the social organization of appointment procedures may explain why transparency and third party endorsements play an important role. Committees' decisions have to be legitimate within a rule- and document-based bureaucratic process. Especially transparency is an important mean of legitimation in such contexts (see Flyverbom et al., 2015). More generally, external peer reviews play an important role for professorial appointments because the appointments have to be legitimate across several contexts: the specific organizational context of the department and the appointing university, the local state $[$ Land $]$ ministry that formally appoints and funds professors, as well as the research field that is eagerly observing to whom the scarce position of a full professorships is awarded.

Career gatekeepers in stand-up comedy legitimize their decisions via third party endorsements as well, but the selection process also derives legitimacy from its ritual-like organization: The JFL Festival has become a rite of passage for up and coming stand-up comedians which is staged in a public and highly ritualized form. The form of this selection process, in turn, may be seen as a response to the distinct structure of careers in creative industries such as stand-up comedy. Careers in stand-up comedy take the form of a sequence of projects and short-term contracts, and comedians may be hired by entertainment organizations for a range of different jobs (Reilly, 2017). Under these conditions, a public audition that serves as a marketplace for the discovery and selection of talent (such as the festival's New Faces series) is more efficient than a conventional hiring process that is tailored to a specific position with clearly defined responsibilities. It is important to keep in mind that the differences in evaluative gatekeeping practices revealed in this paper are gradual. For example, although we have found that one difference between career gatekeeping in academia and stand-up comedy is the reliance on professional categories in academia and 
These are proofs of the final publication available at Springer via American Journal of Cultural Sociology: https://doi.org/10.1057/s41290-019-00078-7

on ascriptive categories in stand-up comedy, we can assume that both professional and ascriptive categories play a role for typecasting in both cases. Likewise, the difference between legitimacy through transparency and legitimacy through ritualization is also not absolute, but a matter of degree. Just as social life in general is permeated by ritual-like performances (Alexander, 2004), professorial appointment procedures can have a ritual-like character as well.

While our comparative approach allowed us to draw attention to variation in career gatekeeping processes in cultural fields, the comparative design of our study also comes with some limitations. First, we compare two cases of career gatekeeping that are not only embedded in two different cultural fields, but also in two different historical and cultural contexts. For some of the differences we reveal in this paper, it is likely that they are at least partly the product of the particular historical and cultural contexts our two cases are situated in. For example, the finding that typecasting processes in stand-up comedy revolve more heavily around ascriptive categories than in academia could be partially the product of a period effect: our data on appointment procedures in German academia spans a period from the 1950 s to the 1980 s, yet it is only in the last few decades that questions of diversity have become more salient in German academia and that universities have embraced policies of equal opportunity. Although we assume ascriptive criteria to be indeed very influential in our period of study (for example, only six of the 199 candidates in our sample are female), only today's policies of equal opportunity and diversity would make the criteria visible in official documents.

Second, some of the results of our cross-field comparison require interpretative caution because we used different methodological approaches to gain insights in to the evaluative practices of career gatekeepers. It is therefore possible that some of the differences that we document may partly be the result of the different methods and data that our two case studies rely on. For example, our material collected from university archives gives professorial 
These are proofs of the final publication available at Springer via American Journal of Cultural Sociology: https://doi.org/10.1057/s41290-019-00078-7

appointments the appearance of being rather formalized procedures in which gatekeepers conduct their assessments in a fairly systematic fashion. The finding that the legitimation of gatekeeping decisions is partly produced through practices of transparency could also have been enhanced by the specific methodological approach: We rely on archived materials that have been produced and preserved for the exact purpose of making the selection process appear transparent. Likewise, participant observation and interviews are methods that require a presence of the researcher on site, observing gatekeeping processes as they unfold. This might invoke the impression that gatekeepers' assessments during the JFL Festival are mostly spontaneous and led by gut-feeling.

We are not able to eliminate these and other limitations entirely due to the different methods and data that our case studies rely on. However, since the main aim of our comparison is to reveal variation in gatekeeping processes, the validity of our findings does not necessarily depend on controlling the differences between our two cases.

\section{CONCLUSION}

Our study contributes to research on career gatekeeping processes in cultural fields by drawing attention to variation in how career gatekeepers make selection decisions for established positions and how these decisions are validated. Leveraging the analytical strength of a cross-case comparison, we show that career gatekeepers deploy seemingly uniform practices such as typecasting, comparison, and legitimation, in different ways. We argue that these differences in gatekeeping practices may be related to the social organization of career gatekeeping processes, and the characteristics of labor markets and career structures in which cultural producers compete with each other.

More research is needed to further examine the relationship between career gatekeeping practices and their social and organizational context. Such research may not only provide 
These are proofs of the final publication available at Springer via American Journal of Cultural Sociology: https://doi.org/10.1057/s41290-019-00078-7

insights into how gatekeeping processes may articulate in different forms across cultural fields, but also how the social and organizational context of gatekeeping processes inform gatekeepers' situated decision making practices. Another strand of future research could continue the line of analysis started here and examine cross- (as well as within) field variation in the practices that career gatekeepers rely on to make selection decisions and validate their decisions. In doing so, research might identify additional gatekeeping practices beyond typecasting, comparisons, and legitimation, or reveal yet different ways in which these practices are enacted. Such research could also examine to what extent variation in gatekeepers' practices may have implications for the outcomes of career gatekeeping processes and social inequalities in cultural fields more generally. For example, scholars might ask whether gatekeeping processes that involve systematic (rather than ad-hoc) comparisons advantage candidates with certain attributes over others, or how typecasting based on ascriptive rather than professional criteria affects the career prospects of cultural producers.

Irrespective of the specific directions of future research, we believe that more scholarship on career gatekeeping is needed because of the critical role that gatekeeping plays in shaping processes of social mobility in cultural fields. In most cultural fields, career gatekeepers routinely introduce discontinuities between contenders which can then translate into larger and more sustained differences in prestige and material resources through processes of cumulative advantage which are difficult to stop once they are set in motion (cf. Menger, 2014; Merton, 1968). A better understanding of career gatekeeping processes is therefore important not only for students of cultural mediation, but also scholars interested in the production and reproduction of inequality in cultural fields. 


\section{REFERENCES}

Alexander, J.C. (2004) Cultural Pragmatics: Social Performance Between Ritual and Strategy. Sociological Theory 22(4): 527-573.

Alexander, J.C. and Smith P. (2003) The Strong Program in Cultural Sociology: Elements of a Structural Hermeneutics. In: Alexander JC (ed) The Meanings of Social Life. A Cultural Sociology. Oxford: Oxford University Press, pp. 11-26.

Angermuller, J. (2017) Academic careers and the valuation of academics. A discursive perspective on status categories and academic salaries in France as compared to the U.S., Germany and Great Britain. Higher Education 73(6): 963-980.

Bechky, B.A. and O'Mahony S. (2015) Leveraging Comparative Field Data for Theory Generation. In: Elsbach KD and Kramer RM (eds) Handbook of Qualitative Organizational Research. Innovative Pathways and Methods. New York: Routledge, pp. 168-176.

Bessy, C. and Chauvin P.-M. (2013) The Power of Market Intermediaries: From Information to Valuation Processes. Valuation Studies 1(1): 83-117.

Bielby, W.T. and Bielby D.D. (1994) All Hits are Flukes. Institutionalized Decision-Making and the Rhetoric of Network Prime-Time Program Development. American Journal of Sociology 99(5): 1287-1313.

Bielby, W.T. and Bielby D.D. (1999) Organizational Mediation of Project-Based Labor Markets: Talent Agencies and the Careers of Screenwriters. American Sociological Review 64(1): 64-85.

Bourdieu, P. (1993) The Field of Cultural Production, Cambridge: Polity Press.

Bystryn, M. (1978) Art Galleries as Gatekeepers. Social Research 1978(45): 390-408.

Cattani, G., Ferriani S. and Allison P.D. (2014) Insiders, Outsiders, and the Struggle for Consecration in Cultural Fields. A Core-Periphery Perspective. American Sociological Review 79(2): 258-281.

Childress, C. and Nault J.-F. (2018) Encultured Biases: The Role of Products in Pathways to Inequality. American Sociological Review 84(1): 115-141.

Chong, P., Lamont M. and Bourgoin A. (2019) The Blackboxing of Expert Judgment: Fiction Reviewing, Scholarly Evaluation and Management Consulting, Unpublished manuscript.

Chong, P.K. (2013) Legitimate judgment in art, the scientific world reversed? Maintaining critical distance in evaluation. Social Studies of Science 43(2): 265-281.

Clayman, S.E. and Reisner A. (1998) Gatekeeping in Action: Editorial Conferences and Assessments of Newsworthiness. American Sociological Review 63(2): 178-199.

Collins, R. (2004) Interaction Ritual Chains, Princeton: Princeton University Press.

Corra, M. and Willer D. (2002) The Gatekeeper. Sociological Theory 20(2): 180-207.

Darr, A. and Mears A. (2017) Locating local knowledge in global networks: Scouting in fashion and football. Poetics 62(2): 1-14.

Dowd, T.J. and Pinheiro D.L. (2013) The Ties among the Notes: The Social Capital of Jazz Musicians in Three Metro Areas. Work and Occupations 40(4): 431-464.

Dubois, S. and François P. (2013) Career Paths and Hierarchies in the Pure Pole of the Literary Field: The Case of Contemporary Poetry. Poetics 41(5): 501-523.

Faulkner, R.R. (1983) Music on Demand: Composers and Careers in the Hollywood Film Industry, New Brunswick: Transaction Books.

Flyverbom, M., Christensen L.T. and Krause Hansen H. (2015) The Transparency-Power Nexus: Observational and Regularizing Control. Management Communication Quarterly 29(3): 385-410. 
Foster, P., Borgatti S.P. and Jones C. (2011) Gatekeeper search and selection strategies: Relational and network governance in a cultural market. Poetics 39(4): 247-265.

Franssen, T.P. and Kuipers G. (2013) Coping with uncertainty, abundance and strife: Decisionmaking processes of Dutch acquisition editors in the global market for translations. Poetics 41(1): 48-74.

Friedman, S. (2014) The hidden tastemakers: Comedy scouts as cultural brokers at the Edinburgh Festival Fringe. Poetics 44(2014): 22-41.

Friedman, S. and O'Brien D. (2017) Resistance and Resignation: Responses to Typecasting in British Acting. Cultural Sociology 11(3): 359-376.

Garfinkel, H. (1967) Studies in Ethnomethodology, Englewood Cliffs, NJ: Prentice Hall.

Godart, F.C. and Mears A. (2009) How Do Cultural Producers Make Creative Decisions? Lessons from the Catwalk. Social Forces 88(2): 671-692.

Greenfeld, L. (1988) Professional Ideologies and Patterns of 'Gatekeeping': Evaluation and Judgment Within Two Art Worlds. Social Forces 66(4): 903-925.

Guetzkow, J., Lamont M. and Mallard G. (2004) What is Originality in the Humanities and the Social Sciences? American Sociological Review 69(2): 190-212.

Hirschauer, S. (2010) Editorial Judgements: A Praxeology of 'Voting' in Peer Review. Social Studies of Science 40(1): 71-103.

Janssen, S. and Verboord M. (2015) Cultural Mediators and Gatekeepers. In: Wright JD (ed) International Encyclopedia of the Social \& Behavioral Sciences. Oxford: Elsevier, pp. 440-446.

Khaire, M. (2017) Culture and Commerce: The Value of Entrepreneurship in Creative Industries, Stanford: Stanford University Press.

Klawitter, M. (2015) Effects of institutional changes on requirements for vacant professorships in Germany. Working Papers in Higher Education Studies 1(2): 1-19.

Lamont, M. (2009) How Professors Think. Inside the Curious World of Academic Judgement, Cambridge, MA: Harvard University Press.

Lamont, M. (2012) Toward a Comparative Sociology of Valuation and Evaluation. Annual Review of Sociology 38(21): 201-221.

Lamont, M. and Swidler A. (2014) Methodological Pluralism and the Possibilities and Limits of Interviewing. Qualitative Sociology 37(2): 153-171.

Lane, C. (2013) Taste makers in the "fine-dining" restaurant industry: The attribution of aesthetic and economic value by gastronomic guides. Poetics 41(4): 342-365.

Leschziner, V. and Green A.I. (2013) Thinking About Food and Sex: Deliberate Cognition in the Routine Practices of a Field. Sociological Theory 31(2): 116-144.

Lewin, K. (1943) Forces behind food habits and methods of change. Bulletin of the National Research Council 108(35-65.

Lincke, H.-J. and Paletschek S. (2002) Situation des wissenschaftlichen Nachwuchses im Fach Geschichte: Berufungsaussichten und Karrierestadien von Historikern und Historikerinnen an deutschen Universitäten Ergebnisse einer Erhebung im Jahr 2002, Universität Freiburg: Manuskript.

McCarthy, S.L. (2016) Nick Brazao, Just for Laughs New Faces and Off-JFL Producer. The Comic's Comic. Available at: http://thecomicscomic.com/2016/05/30/episode-93-nickbrazao-just-for-laughs-new-faces-and-off-jfl-producer, accessed 18 June 2019.

Mears, A. (2014) Seeing Culture through the Eye of the Beholder: Four Methods in Pursuit of Taste. Poetics 43(3): 291-309.

Menger, P.-M. (2014) The Economics of Creativity. Art and Achievement under Uncertainty, Cambridge: Harvard University Press.

Merton, R.K. (1968) The Matthew Effect in Science. Science 159(3810): 56-63.

Möhlmann, S. (2014) Autonomie konkret: die Ruferteilung. Wer beruft nach welchem Verfahren? Forschung \& Lehre 10(2014): 808-809. 
Muniesa, F. and Helgesson C.-F. (2013) Valuation studies and the spectacle of valuation. Valuation Studies 1(2): 119-123.

Musselin, C. (2010) The market for academics, New York: Routledge.

Nylander, E. (2014) Mastering the Jazz Standard. Sayings and Doings of Artistic Valuation. American Journal of Cultural Sociology 2(1): 66-96.

Posselt, J.R. (2016) Inside Graduate Admissions. Merit, Diversity, and Faculty Gatekeeping, Cambridge, MA: Harvard University Press.

Power, M. (1997) The Audit Society. Rituals of Verification, Oxford: Oxford University Press.

Prior, L. (2008) Repositioning Documents in Social Research. Sociology 42(5): 821-836.

Prior, L. (2012) Using Documents in Research, Los Angeles: Sage.

Reilly, P.M. (2017) The Layers of a Clown. Career Development in Cultural Production Industries. Academy of Management Discoveries 3(2): 145-164.

Roussel, V. and Bielby D.D. (2015) Brokerage and Production in the American and French Entertainment Industries: Invisible Hands in Cultural Markets. Lanham: Lexington Books.

Shoemaker, P.J. and Vos T. (2009) Gatekeeping Theory, London: Routledge.

van den Brink, M. and Benschop Y. (2012) Gender practices in the construction of academic excellence: Sheep with five legs. Organization 19(4): 507-524.

van den Brink, M. and Benschop Y. (2014) Gender in Academic Networking: The Role of Gatekeepers in Professorial Recruitment. Journal of Management Studies 51(3): 460492.

Velthuis, O. (2003) Symbolic meanings of prices: Constructing the value of contemporary art in Amsterdam and New York galleries. Theory and Society 32(2): 181-215.

Verboord, M. (2011) Market logic and cultural consecration in French, German and American bestseller lists, 1970-2007. Poetics 39(4): 290-315.

Verdaasdonk, H. (2001) Reviews, Critics, and Cultural Gatekeepers. In: Smelser NJ and Baltes PB (eds) International Encyclopedia of Social \& Behavioral Sciences. pp. 1329513299.

Vermurlen, B. (2016) Structural overlap and the management of cultural marginality: The case of Calvinist hip-hop. American Journal of Cultural Sociology 4(1): 68-106.

Zuckerman, E.W. (2012) Construction, Concentration, and (Dis)Continuities in Social Valuations. Annual Review of Sociology 38(2012): 223-245.

Zuckerman, E.W., Kim T.-Y., Ukanwa K., et al. (2003) Robust Identities or Nonentities? Typecasting in the Feature-Film Labor Market. American Journal of Sociology 108(5): 1018-1074. 